\title{
Collective and Individual Wrongdoing
}

\author{
Joseph Adams \\ University of Nottingham
}

\begin{abstract}
Collectively, we might think, the near 63 million people who voted for Donald Trump in 2016 did something wrong. But did any of these voters individually do anything wrong? None of their individual votes, after all, made any difference to the outcome of the election. So do these voters bear any individual responsibility for voting the way they did? Can we ever bear individual responsibility for how we vote in elections, or only ever 'collective' responsibility? Is it appropriate to blame individuals when they vote for morally questionable candidates?

Similarly, we might say that a group of thugs who jointly attack an innocent victim collectively do something wrong, but wonder whether any of them individually do anything wrong. For it might be that none of the thugs' individual contributions to the attack make any difference to the victim's suffering. Does each individual thug deserve to be punished for their own part in the attack?
\end{abstract}

Here, I argue that, other things being equal, in these cases of apparent collective wrongdoing, none of the individuals in question do anything wrong. Other things being equal, none of those 63 million people did anything wrong by voting for Trump, and none of the thugs did anything wrong by participating in the attack.

This conclusion may appear shocking. To mitigate its import, I argue that we can appropriately blame many of the Trump-voting individuals, and that the thugs involved in the attack do individually deserve to be punished. For we need not think that blameworthiness, or desert of punishment, must always be based on the fact that one has done something wrong. We can blame Trump voters, and punish thugs, not for anything they have done, but simply for being the kind of people they are.

Keywords: blame; justice; punishment; responsibility; voting 